\title{
Geologic map of the Fawnskin 7.5' quadrangle, San Bernardino County, California
}

\author{
By F.K. Miller ${ }^{3}$, J.C. Matti ${ }^{2}$, H.J. Brown, and R.E. Powell ${ }^{3}$ \\ Digital preparation by Gregory Morton ${ }^{1}$, Steven Kennedy ${ }^{2}$, and P.M. Cossette ${ }^{3}$ \\ Prepared in cooperation with \\ CALIFORNIA DIVISION OF MINES AND GEOLOGY \\ and U.S. FOREST SERVICE, SAN BERNARDINO NATIONAL FOREST \\ Open-File Report OF 98-579 \\ Version 1.1
}

2001

Any use of trade, product, or firm names is for descriptive purposes only and does not imply endorsement by the U. S. Government. This database, identified as "Digital geologic map of the Fawnskin 7.5' quadrangle, San Bernardino County, California " has been approved for release and publication by the Director of the USGS.

\section{U. S. DEPARTMENT OF THE INTERIOR \\ U. S. GEOLOGICAL SURVEY}

${ }^{1}$ Western Earth Surface Processes Team, U.S. Geological Survey

U.S. Geological Survey, Department of Earth Sciences, University of California, Riverside, CA 92521

${ }^{2}$ Western Earth Surface Processes Team, U.S. Geological Survey

920 Park Avenue, Tucson, AZ 85719

${ }^{3}$ U.S. Geological Survey

904 West Riverside Avenue, Spokane, WA 99201 


\section{TABLE OF CONTENTS}

Introduction

General

How to obtain paper plots

Database contents

Data package

Plot package

Other files

Software utilities

How to obtain the digital files

How to extract the geologic map database from the tar file

Digital database

PostScript plot files

Portable Document Format (.pdf) files

How to convert the ARC/INFO interchange (export) files

Digital geologic map specifications

Digital and geologic compilation of geologic map

Base map

Spatial resolution

Map accuracy standards

Database specifics

General

Lines

Polygons

Points

References

Appendix I

\section{INTRODUCTION}

\section{General}

Open-File Report OF 98-579 version 1.1 contains a digital geologic map and map database of the Fawnskin 7.5' quadrangle, San Bernardino County, California that includes:

1. ARC/INFO (Environmental Systems Research Institute, http://www.esri.com) version 7.2.1 double precision coverages of the various elements of the geologic map

2. A PostScript file to plot the geologic map on a topographic base, and containing a Correlation of Map Units diagram, and Description of Map Units.

3. Portable Document Format (.pdf) files of:

a. This Readme; includes in Appendix I, data contained in fskn_met.txt

b. The same graphic as plotted in 2 above. (Test plots from this .pdf do not produce 1:24,000-scale Maps. Adobe Acrobat pagesize settings control map scale.)

This release includes features not found in most other digital geologic maps, in that all polygons, lines, and points in the coverage are encoded with detailed, comprehensive geologic data contained in six INFO data tables (.rel) (see Matti and others, 1998a, 1998b, and 1998c for information on how the encoding may be accessed and utilized). No paper map is included in the Open-File report, but a PostScript plot file containing an image of the geologic map sheet, topographic base, Correlation of Map Units (CMU), and detailed Description of Map Units (DMU) is. The Correlation of Map Units and Description of Map Units is in the editorial format of USGS Miscellaneous Investigations Series (Iseries) maps but has not been edited to comply with I-map standards. Within the geologic map data package, map units are identified by standard geologic map criteria such as formation-name, age, and lithology. Even though this is an author-prepared report, every attempt has been made to closely adhere to the stratigraphic nomenclature of the U. S. 
Geological Survey. Descriptions of units can be obtained by viewing or plotting the .pdf file ( $3 b$ above) or plotting the postscript file ( 2 above). If roads in some areas, especially roads that parallel topographic contours, do not show well on plots of the geologic map, we recommend use of the USGS Fawnskin 7.5' topographic quadrangle in conjunction with the geologic map.

This README file describes the digital data, such as types and general contents of files making up the database, and includes information on how to extract and plot the map and accompanying graphic file. Metadata information can be accessed at http://geo-nsdi.er.usgs.gov/cgi-bin/publication?map-of and is included in Appendix I, Readme.

\section{HOW TO OBTAIN PAPER PLOTS}

Paper plots may be made on large-format plotters such as HP650C, HP755C, and HP2500C directly from the included PostScript plot file. At this time, the USGS does not make or distribute plots of Open-File maps.

\section{DATABASE CONTENTS}

The files constituting the geologic map database of this Open-File Report are listed below along with the interchange files from which they are extracted.

\section{Data Package}

All files listed below are in a compressed tar file named fskn.tar.gz (5.5 Mb); see section below titled, SOFTWARE UTILITIES.

\begin{tabular}{|c|c|c|}
\hline $\begin{array}{l}\text { ARC/INFO } \\
\text { interchange files } \\
\end{array}$ & $\begin{array}{l}\text { Fawnskin } \\
\text { coverages }\end{array}$ & Contains \\
\hline fskn_geo.e00 & fskn_geo & $\begin{array}{l}\text { Contacts, faults, geologic unit labels Annotation } \\
\text { subclasses: GEO unit labels (plot) FAULT fault } \\
\text { formal names (plot) }\end{array}$ \\
\hline fskn_pts.e00 & fskn_pts & $\begin{array}{l}\text { Attitudes and their dip values. Dip values } \\
\text { plotted as annotation. }\end{array}$ \\
\hline fskn_str.e00 & fskn_str & Linear structural data \\
\hline fskn_orn.e00 & fskn_orn & Geologic line ornamentation \\
\hline fskn ldr.e00 & fskn ldr & Leaders for polygon labels and fault names \\
\hline lines.rel.e00 & lines.rel & Line dictionary \\
\hline points.rel.e00 & points.rel & Point dictionary \\
\hline scamp2.shd.e00 & scamp2.shd & SCAMP shade set \\
\hline fawnskin_summary.e00 & fawnskin_summary.rel & Coded geologic data; see Appendix I \\
\hline fawnskin_lithology.e00 & fawnskin_lithology.rel & Coded geologic data; see Appendix I \\
\hline fawnskin_structure.e00 & fawnskin_structure.rel & Coded geologic data; see Appendix I \\
\hline fawnskin genesis.e00 & fawnskin genesis.rel & Coded geologic data; see Appendix I \\
\hline fawnskin_protolith.e00 & fawnskin_protolith.rel & Coded geologic data; see Appendix I \\
\hline fawnskin_paleontology.e00 & fawnskin_paleontology.rel & Coded geologic data; see Appendix I \\
\hline
\end{tabular}

The directory, info/, is produced in the process of importing interchange files to ARC coverages and data files in ARC/INFO. The Fawnskin info/ directory contains:

$\underline{\text { Feature Attribute tables }}$

$\begin{array}{ll}\text { Polygon attribute table } & \text { fskn_geo.pat } \\ \text { Arc attribute tables } & \text { fskn_geo.aat } \\ & \text { fskn_ldr.aat } \\ & \text { fskn_str.aat } \\ \text { Point attribute tables } & \text { fskn_pts.pat } \\ & \text { fskn_orn.pat }\end{array}$


$\underline{\text { INFO data tables }}$

\section{fawnskin_summary.rel \\ fawnskin_lithology.rel \\ fawnskin_structure.rel \\ fawnskin_genesis.rel \\ fawnskin_protolith.rel \\ fawnskin_paleontology.rel \\ lines.rel \\ points.rel}

$\underline{\text { Raster file }}$

fskn.tif

$\underline{\text { Resultant image }}$

Fawnskin basemap
Contains data unique to Fawnskin quadrangle

Contains data unique to Fawnskin quadrangle

Contains data unique to Fawnskin quadrangle

Contains data unique to Fawnskin quadrangle

Contains data unique to Fawnskin quadrangle

Contains data unique to Fawnskin quadrangle

Dictionary, contains all SCAMP line codes

Dictionary, contains all SCAMP point codes

\section{$\underline{\text { ASCII text file }}$}

poly_attrib_code.txt

Polygon attribute codes listed alphabetically and their explanations.

(Matti and others, 1998a)

\section{Plot Package}

PostScript plot files of the geologic map and CMU/DMU; please see section below titled, SOFTWARE UTILITIES for additional information.

\section{$\underline{\text { Compressed file }} \quad \underline{\text { Resultant image }} \quad \underline{\text { Contains }}$}

fskn_map.ps.gz

fskn_map.ps

PostScript plot file of geologic map and CMU/DMU

PostScript files are compressed UNIX files requiring gzip to uncompress them.

The uncompressed PostScript file fskn_map.ps will plot a 1:24,000 scale, full color geologic map of the Lakeview quadrangle on a topographic base. A detailed CMU diagram, a DMU, and a regional structure map are included on the sheet. This sheet is in the editorial format of the U.S. Geological Survey's Miscellaneous Investigations (I) map series, and is approximately 45 X 32 inches in size. The map sheet has been successfully plotted on Hewlett-Packard large-format plotters, models HP650C, HP755CM, and HP2500C.

\section{Other files}

\section{Readme.pdf fskn_map.pdf poly_attrib_code.pdf}

This document in .pdf format Geologic map, DMU, and CMU

Alphabetical listing of polygon codes and code explanations

\section{SOFTWARE UTILITIES}

Files which have .gz file extension were compressed using gzip. Gzip utilities are available free of charge via the internet at the gzip home page, http://www.gzip.org

The data package is additionally bundled into a single tar (tape archive) file. Individual files must be extracted using a tar utility, available free of charge via the internet through links on the Common Internet File Formats page, 
http://www.matisse.net/files/formats.html. One such utility is WinZip, available at http://www.winzip.com (WinZip can also decompress files).

Files in the plot package have been prepared to produce optimum plots using the shade, and marker sets listed below. The marker, line and shade (pattern) sets may be obtained at the web site

http://wrgis.wr.usgs.gov/docs/ncgm/scamp/scamp.html.

Geoage font group may be obtained at the following web site

Server: onyx.wr.usgs.gov

UserID: anonymous

Password:Your e-mail address

Directory: pub/wpg/supplies/geoage

$\begin{array}{ll}\text { geoscamp2.lin } & \text { Lines } \\ \text { geoscamp2.mrk } & \text { Points } \\ \text { scamp2.shd } & \text { Colors (included in data package) } \\ \text { geology2.shd } & \text { Patterns } \\ \text { Geoage font group } & \text { Geologic Age Symbols }\end{array}$

\section{HOW TO OBTAIN THE DIGITAL FILES}

The export files, and subsequently the data and plot files, constituting the geologic map database of this Open-File Map may be obtained in two ways, both over the Internet.

1. The files can be obtained via the Web from Western Region Geologic Information Server. Go to the web page at http://geopubs.wr.usgs.gov/open-file/of98-579 and follow the directions to download the files.

2. The files can also be obtained by anonymous ftp over the Internet from wrgis.wr.usgs.gov. The files are located in the directory /pub/open-file/of98-579. Be sure to use binary transfer mode or ASCII mode for individual .e00 files (ARC interchange file format).

3. Metadata can be obtained at http://geo-nsdi.er.usgs.gov/cgi-bin/publication?open-file

\section{HOW TO EXTRACT THE GEOLOGIC MAP DATABASE FROM THE TAR FILE}

After downloading the files, they must be uncompressed using a gzip utility such as gzip itself or WinZip. The data files must then be extracted using a tar utility.

This process will create a directory, fskn/, that contains the ARC/INFO interchange files and supporting files. The directory should contain the following files:

\section{fskn/}

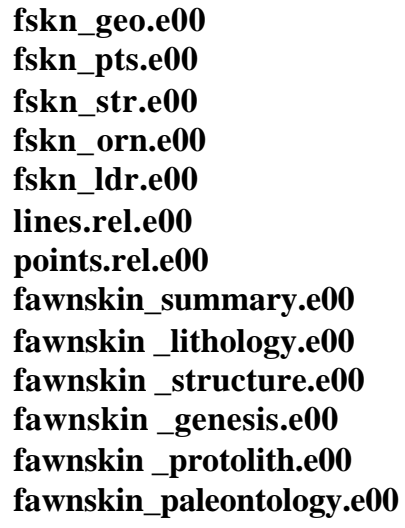




\title{
fskn.tif
}

poly_attrib_code.txt

The following are not included in the database tar file, and are downloaded separately

\author{
fskn_map.ps.gz \\ poly_attrib_code.pdf \\ Readme.pdf \\ fskn_map.pdf
}

\section{PostScript plot files}

Make a 21 MB uncompressed file, fskn_map.ps (plot of complete map), by typing gzip -d fskn_map.gz (or use gzip utility of choice) and/or

\section{Portable Document Format (.pdf) files}

PDF files are not stored as gzip files. They are accessed using Adobe Acrobat Reader software, available free from the Adobe website http://www.adobe.com. Follow instructions at the website to download and install the software. Acrobat Reader contains an on-line manual and tutorial.

\section{HOW TO CONVERT THE ARC/INFO INTERCHANGE (EXPORT) FILES}

The ARC interchange (.e00) files are converted to ARC coverages using the ARC command IMPORT.

ARC interchange files can also be read by some other Geographic Information Systems, including ArcView (ESRI) and MapInfo (http://www.mapinfo.com) (Environmental Systems Research Institute, Inc, 1991). Please consult your GIS documentation to see if you can use ARC interchange files and the procedure to import them.

\section{DIGITAL GEOLOGIC MAP SPECIFICATIONS}

\section{Digital and geologic compilation of geologic map}

The geologic map information was hand digitized from a base-stable original (ink on a greenline) of the geologic map at 1:24,000 scale. Digital tics were placed by hand at latitude/longitude intersections. The lines, points, and polygons were edited using standard ARC/INFO commands, and in some places, interactively by hand using graphical user interface ALACARTE (Fitzgibbon, 1991, Fitzgibbon and Wentworth, 1991, Wentworth and Fitzgibbon, 1991). Digitizing and editing artifacts significant enough to display at a scale of 1:24,000 were corrected.

\section{Base map}

The base map image (fskn.tif, Geotiff format) was prepared by scanning a scale-stable clear film of the U.S Geological Survey, 1:24,000 Fawnskin 7. 5' quadrangle (1967) topographic map. Scanning was done using an Anatech Eagle 4080 monochrome 800 dpi scanner at a resolution of 500 dpi. The raster scan was converted to a monochromatic image in ARC/INFO, and registered and rectified to the Fawnskin 7.5' quadrangle. No elements of the base layer are attributed. The base map is provided for reference only.

\section{Spatial resolution}

Use of this digital geologic map database should not violate the spatial resolution of the data. Although the digital form of the data removes the constraint imposed by the scale of a paper map, the detail and accuracy inherent in map scale are also present in the digital data. The fact that this database was edited at a scale of 1:24,000 means that higher resolution information is not generally present in the dataset. Plotting at scales larger than 1:24,000 
will not yield greater real detail, although it may reveal fine-scale irregularities above the intended resolution of the database. Similarly, although higher resolution data is incorporated at some places, the resolution of the combined output will be limited by the lower resolution data.

\section{Map accuracy standards}

Until uniform National geologic map accuracy standards are developed and adopted, lines and points on SCAMP 1:24,000 scale geologic maps that are located to within 15 meters, relative to accurately located features on the base map, are considered to meet map accuracy standards. Dashed lines, indicated in the database coding as not meeting map accuracy standards, are generally located to within 30 meters, relative to accurately located features on the base map.

\section{Database specifics}

General-The map database consists of ARC/INFO format coverages which are stored in polyconic projection (Table 1), and a series of data tables. Digital tics define a 7.5-minute grid of latitude and longitude in the geologic coverages corresponding to the 7.5-minute tic grid on the topographic base map.

\begin{tabular}{|c|c|}
\hline Projection & Polyconic \\
\hline Datum & NAD27 \\
\hline Zunits & No \\
\hline Units & Meters \\
\hline Spheroid & Clark 1866 \\
\hline X shift & 0.0000000000 \\
\hline Y shift & 0.0000000000 \\
\hline \multirow{2}{*}{\multicolumn{2}{|c|}{341500 latitude of projection's origin }} \\
\hline & \\
\hline \multicolumn{2}{|c|}{0.00000 false easting (meters) } \\
\hline 0.0000 & northing (meters) \\
\hline
\end{tabular}

The content of the geologic database can be described in terms of feature classes that include lines, points, and areas that comprise the map. See the metadata text file (Appendix I) for detailed descriptions.

Lines-Lines are recorded as strings of arcs and are described in an arc attribute (.aat) table in Appendix I. They represent contacts and faults which define the boundaries of map units and map boundaries.

Polygons-Geologic map units (polygons) are described in the polygon attribute table in Appendix I. In addition, using a system developed under the Southern California Areal Mapping Project (SCAMP), the Lake view quadrangle is encoded with detailed, polygon-specific geologic information on a polygon-by-polygon basis, so that within the quadrangle, lateral variations in a particular map unit can be recorded in the map database. For traditional descriptions of the map units, see the Portable Document Format file fskn_map.pdf. A list of all map units in the database is given in Appendix I.

Points-Point information (attitudes of planar and linear features, and line ornamentation) is recorded as coordinate and related information and is given in Appendix I.

Overview of data table (.rel) contents - In each data table the items TAG (polygons), L-TAG (lines), and P-TAG (points) are the common items enabling users to establish relate environments that provide flexibility and access to as much or as little of the encoded, detailed geologic data as required (A complete description of the line, point, and polygont data coding schemes is available in Matti and others, 1998a, b, and c).

$\underline{\text { Data Table }}$

fawnskin_summary.rel $\underline{\text { Attribute Data }}$

- contains general, geologic information about age, 
fawnskin_lithology. rel

fawnskin_structure. rel

fawnskin_genesis. rel

fawnskin_protolith. rel

fawnskin_paleontology.rel

lines.rel

points.rel rock type, rock-unit classification, and origin - contains lithologic attributes for each of five major rock types that occur within a geologic-map rock unit - contains geologic-structure attributes for each of the major rock types

-contains summary attribute data describing the genesis of each of the major rock types

-contains protolith attribute data for each of the major rock types that applies to both metamorphic and straindominated rocks

-contains summary information about fossil types in each of the major rock types

-line dictionary that contains a full description of each line type

-point dictionary that contains a full description of each point type

Coded detailed geologic data - Up to ten data files, consisting of one selected data file and nine related data files can be temporarily joined using the RELATE command. The following is an example of how to establish a simple relate environment and the ARC/INFO dialogue the user will encounter.

At the Arc prompt, type: relate add

Dialogue for ADD

Relation name: name of relate you want to establish

Table identifier: pathname or database table name of the data file

Database name: name of the database in which the data file is stored

Info item: the item name in an INFO data file from which the relate is performed

Relate column: the field in the related table which is related to the INFO item

Relate type: the type of relate performed - one of the following four: LINEAR, ORDERED, LINK, TABLE. LINEAR is the slowest, but the simplest to apply. (Please consult ARC/INFO online help topic such as 'working with tables' for help on selection of relate type)

Relate access: the access rights to the related file: $\mathrm{RW}$, or RO, or AUTO

The table below shows an example using files from the Fawnskin database.

Arc: relate add

Relation name: carbonate

Table identifier: fawnskin_lithology.rel

Database name: info

INFO item: tag

Relate column: tag

Relate type: linear

Relate access: rw

To save a particular relate environment:

Arc: relate save <name of relate>

To restore a particular relate environment:

Arc: relate restore <name of relate> 
To use the relate environment in the selection process:

select <relate name $>/ /<$ item $>\mathrm{cn}$ '.search target.'

An example using Lakeview data:

Ae: select carbonate//lith2 cn '.SEDLC.'

Only the polygon data structure is described below, but the line and point data have similar structure. Coding is accomplished through the use of alpha-numeric characters separated by parsing symbols, dots (.) that separate primary attribute data, and hyphens (-) that separate secondary attribute data. The data base is structured to mimic geologists' methods of describing geologic units and their attributes, that is, beginning with general observations and expanding to progressively more specific details. To parallel this process, the polygon-attribute data base is organized into the following topics:

\author{
General features \\ Major rock type \\ Geologic age \\ General origin \\ Lithology \\ Specific rock type \\ Outcrop character \\ Composition \\ Geologic structures \\ Protolith (metamorphic and high-strain rocks) \\ Genesis of specific rock types \\ Petrography \\ Paleontology \\ Geotechnical properties \\ Penetration resistance \\ Shear-wave velocity \\ Magnetic susceptibility
}

Typically, geologic descriptions are a series of phrases linking various attributes of a map unit. The following example of a unit description and the corresponding coding might best illustrate how the SCAMP encoding system is organized and utilized:

Description: Mill Creek Formation (Miocene)

Main rock-type of Mill Creek Formation is quartzofeldspathic sandstone that is ledgeforming, very pale brown to pale yellow, medium to thick-bedded, well cemented, poorly sorted, pebbly, fine to very coarse sand-size, flat-laminated to ripple-laminated, with rounded pebbles of basalt. Secondary rock type interlayered with main rock type consists of mudrock that is clay-rich, slope-forming, grayish green to brown, laminated to indistinctly bedded, consolidated to indurated, texturally massive to flat-laminated, mud-cracked locally, having calcareous concretions and trace fossils.

In addition to these two lithologic types, the Mill Creek Formation is also:

locally broken by numerous small faults, and all occurrences of the map unit are laced by networks of randomly-oriented fractures, most open but some partially closed with zeolitic cement.

Coding for this unit, given below, reflects the lithologic complexity, and allows search-and-retrieval analysis which targets geologic categories that are as broad or as narrow as the map-user requires. This coding scheme emphasizes relations among related geologic attributes, but also allows clear separation among non-related attributes. The following coding also illustrates how specific data are arranged in INFO data tables.

Coding: Mill Creek Formation (Miocene) 
$\underline{\text { Data table }} \quad \underline{\text { tem }} \quad \underline{\text { Code }} \quad \underline{\text { Code explanations from Polygon-Attribute Code List }}$

Summary.rel

$\begin{array}{ll}\text { TAG } & \text { TmcA } \\ \text { AGE } & \text {.CZOTM.LMAC. } \\ \text { AGECON } & \text {.FSLC. } \\ \text { TYPE } & \text {.BRK.SED.SEDS } \\ \text { CLASS } & \text {.RSCBFF. } \\ & \\ \text { ORIGIN } & \text {.BRDS. }\end{array}$

Unit identifier

.Cenozoic, Miocene.Clarendonian. age based on fossils, age certain. .bedrock.sedimentary.sedimentary, siliclastic. .classification of map unit, bedrock, formal, formation rank.

braided, sand-bed.

Lithology.rel

$\begin{array}{ll}\text { TAG } & \text { TmcA } \\ \text { LITH1 } & \text {.GRK.GRKSSCP. } \\ & \text { QFD.OGML.COLBPV. } \\ & \text { COLYP.BEDMK.INDE. } \\ & \text { GSOP.GSZSVFVC. } \\ & \text { SDSLF.SDSLR.CCOIVB. } \\ \text { LITH2 } & \text {.MRK.MRKM.OGMS. } \\ & \text { COLGE.COLBG.BEDL. } \\ & \text { BEDI.INDCI.SDSMFL. } \\ & \text { SDSMK. }\end{array}$

Unit identifier .grainrock.sandstone, pebbly.quartzofeldspathic. ledge-forming.brown, pale, very.yellow,pale.bedding, medium to thick.indurated.poorly sorted.grainsize, sand, fine to very coarse.lamination, flat.lamination, ripple.clast composition, basalt .mudrock.mudstone.slope-forming.gray, greenish. brown, grayish.bedding, laminated.bedding, indistinct.consolidated to indurated.massive to flat laminated.mud cracks.

Structure.rel

$\begin{array}{ll}\text { TAG } & \text { TmcA } \\ \text { LITH1 } & \text {.SDFNFL.SDFNRO. } \\ & \text { SDFNRCP-FRAR- } \\ \text { LITH2 } & \text {.SDFNFL.SDFNRO. } \\ & \text { SDFNRCP-FRAR- }\end{array}$

Unit identifier

faults, local small.fractures, open.fractures, partly closed-fractures random-

faults, local small.fractures, open.fractures, partly closed-fractures random-

Genesis.rel

$\begin{array}{ll}\text { TAG } & \text { TmcA } \\ \text { LITH1 } & \text {.NMA.ALP.FLUV. } \\ & \text { BRDS. } \\ \text { LITH2 } & \text {.DELPL.MNDF. }\end{array}$

Unit identifier .nonmarine.alluvial-plain.alluvial valley setting. braided sand-bed.

.delta-plain deposits.fine-grained, meandering.

Paleontology.rel

TAG TmcA Unit identifier

LITH1 .FOSN.FOSNP.FOSNT. .nonmarine fossils.nonmarine plants.trace fossils.

Searching the database-The digital database of the Fawnskin quadrangle can be searched in a number of wayseach requiring a basic understanding of both the database structure and ARC/INFO's logical expression syntax in order to take full advantage of ARC/INFO's selection tools. ARC/INFO has a number of selection commands that require the user to construct simple, logical expressions.

\section{For example: Area GT 1000}

<operand1><logical operation><operand2>

Using a selection command (select) the user would be asking for areas greater than $1000 \mathrm{~m}^{2}$

$\underline{\text { ARC/INFO selection commands }}$

SELECT Selects features or data items 
ASELECT Adds to your selected set of items or features

UNSELECT Removes selected features from your group of selected items.

RESELECT Selects a subset of items our of your group of selected items.

NSELECT Unselects all of your currently selected items and selects all those you did not have selected.

All of the selection commands except for NSELECT can be used in conjunction with logical expressions of operators and connectors so that you can select for or against any item that is coded in the database. The table below illustrates some ways to search the polygon data base. The examples use code sentences from two different polygon types (Item 1 and Item 2), using the data-base fields LABL and LITH1 (in LITHOLOGY.rel):

$\underline{\text { Item } 1} \underline{\text { Item } 2}$

LABL: $\quad$ Qal $\quad$ Qyf

LITH1: $\quad$.SDE.ESE.TES.TES.ZXE.SEES.MESE. $\quad$.SDE.ESE.TES.TES.ZXE.SEEB.MEII.

For Items 1 and 2 the two code sentences clearly are related, but they differ slightly in their last two codes.

$\underline{\text { OperatorExample expression Explanation }}$

CN Select LITH1 cn '.SEES.' This is a whole word search which would select sentence one above

CN Select LITH1 cn 'SEE' This is a prefix search that will select all items containing a code stringword with the prefix SEE. In this case both sentence one and two would be selected

CN Select LITH1 cn '.SEES.' This example uses a logical connector, AND, which and LABL cn 'Qal' would select all items that contain SEES and also are of type Qal. In this case, sentence one would be selected

The user can substitute any logical operator or logical connector to search and select for and/or against any combination of items coded in the database. Some of the operators and connectors that are useful include:

\section{Operators:}

CN Contains

NC Not containing

\section{Connectors:}

AND Only items for which the expressions on both side of the AND are true will be selected

OR Items for which the expressions on either side of the OR will be selected

XOR Items for which ONLY one of the expressions on either side of the XOR are true 
will be selected

Query and search of version 1.0 of the Lakeview database will provide the user with CODED output which will require reference to the alphabetical list of polygon attribute codes and their respective explanations

contained in the ASCII text file (poly_attrib_code.txt) included in the database package, fskn.tar.gz. or in the pdf file poly_attrib_code.pdf.

\section{REFERENCES}

Environmental Systems Research Institute, Inc, 1991, ARC/INFO command references 6.0: Proprietary software manual

Matti, J.C., Powell, R.E., Miller, F.K., Kennedy, S.A., Ruppert, K.R., Morton, G.L., and Cossette, P.M., 1998a, Geologic-line attributes for digital geologic map databases produced by the Southern California Areal Mapping Project (SCAMP), Version 1.0: U.S.Geological Survey Open-File Report 97-861

Matti, J.C., Miller, F.K., Powell, R.E., Kennedy, S.A., Bunyapanasarn, T.P., Koukladas, Catherine, Hauser, R.M., and Cossette, P.M., 1998b, Geologic-point attributes for digital geologic map databases produced by the Southern California Areal Mapping Project (SCAMP), Version 1.0: U.S.Geological Survey Open-File Report 97-859

Matti, J.C., Miller, F.K.,Powell, R.E., Kennedy, S.A., and Cossette, P.M., 1998c, Geologic-polygon attributes for digital geologic-map databases produced by the Southern California Areal Mapping Project (SCAMP), Version 1.0: U.S.Geological Survey Open-File Report 97-860 
APPENDIX I

(Original metadata text)

Identification_Information:

Citation:

Citation_Information:

Originator: F.K. Miller

Originator: J.C. Matti

Originator: H.J. Brown

Originator: R.E. Powell

Publication_Date: 1998

Title: Geologic map of the Fawnskin 7.5' quadrangle, San Bernardino County, California

Edition: Version 1.1

Geospatial_Data_Presentation_Form: vector digital data

Series_Information:

Series_Name: U.S. Geological Survey Open-File Report

Issue_Identification: OF 98-579

Publication_Information:

Publication_Place: Menlo Park, California

Publisher: U.S. Geological Survey

Online_Linkage: http://geopubs.wr.usgs.gov/open-file/of98-579

Description:

Abstract:

This data set maps and describes the geology of the Fawnskin 7.5' quadrangle, San Bernardino

County, California and contains original U.S. Geological Survey data generated by detailed field observation and by interpretation of aerial photographs. The geologic map covers part of the northern San Bernardino Mountains. Bedrock units in the San Bernardino Mountains are dominated by large Cretaceous and Jurassic granitic bodies ranging in composition from monzogranite to gabbro, and include lesser Triassic monzonite. These granitic rocks intrude highly faulted and folded Late Proterozoic and Paleozoic formations representative of those found in the southern Great Basin. Low-angle thrust faults, many of them complexly folded, cut the Late Proterozoic and Paleozoic formations. A large, deformed cataclastic zone in the western part of the quadrangle cuts pre-Late Cretaceous units, and is intruded by Late Cretaceous plutons. Spanning the Pleistocene in age, large alluvial fans flank the north side of the mountains, and are dominated by debris flow deposits. Young, south dipping reverse faults, some with moderately to well eroded fault scarps, discontinuously flank the northern edge of the mountains. Young and old high-angle faults are mapped within the range.

Created using Environmental Systems Research Institute's ARC/INFO software, the database consists of the following items: (1) a map coverage containing faults, geologic contacts and units, (2) a coverage showing structural point data, (3) a coverage containing linear structural data, (4) a coverage showing geologic line ornamentation and (5) six additional INFO data tables (.rel) that contain detailed, coded, geologic information such as texture, fabric, color, and mineralogy,. These additional data are accessible to the user through the utilization of ARC/INFO relate environments and provide the user access to as much or as little of the encoded data as required. In addition, the data set includes the following graphic and text products: (1) A PostScript graphic plot-file containing the geologic map, topography, cultural data, a Correlation of Map Units (CMU) diagram, a Description of Map Units (DMU), and a key for point and line symbols; (2) PDF files of this Readme (including the metadata file as an appendix), Description of Map Units (DMU), and a screen graphic of the plot produced by the PostScript plot file.

The geologic map database contains original U.S. Geological Survey data generated by detailed field observation and by interpretation of aerial photographs. Within the 
database, geologic contacts are represented as lines (arcs), geologic units as polygons, and site-specific data as points. Polygon, arc, and point attribute tables (.pat, .aat, and .pat, respectively) uniquely identify each geologic datum.

Version 1.1 of this digital release differs from Version 1.0 mainly by changes and additions to conform to the more recently released digital geologic map of the Butler Peak quadrangle (OF 00-145), which adjoins the Fawnskin quadrangle on the west. Along the western edge of the quadrangle several polygons of Quaternary units are added and the names of several are changed. Colors of some granitic units are changed to conform to colors assigned to the same units in the Butler Peak quadrangle.

Purpose:

The data set for the Fawnskin quadrangle has been prepared by the Southern California Areal Mapping Project (SCAMP), a cooperative project sponsored jointly by the U.S. Geological Survey and the California Division of Mines and Geology, as part of an ongoing effort to utilize a Geographical Information System (GIS) format to create a regional digital geologic database for southern California. This regional database is being developed as a contribution to the National Geologic Map Data Base of the National Cooperative Geologic Mapping Program ofthe USGS. Development of the data set for the Fawnskin quadrangle has also been supported by the U.S. Forest Service, San Bernardino National Forest.

The digital geologic map database for the Fawnskin quadrangle has been created as a general-purpose data set that is applicable to other land-related investigations in the earth and biological sciences. For example, the U.S. Forest Service, San Bernardino National Forest, is using the database as part of a study of an endangered plant species, California Buckwheat, that shows preference for particular rock types. The Fawnskin database is not suitable for site-specific geologic evaluations at scales greater than $1: 24,000(1$ in $=2,000 \mathrm{ft})$.

Supplemental_Information:

Within the geologic map database, map units are identified by standard geologic map criteria such as formation-name, age, and lithology. The authors have attempted to adhere to the stratigraphic nomenclature of the U.S. Geological Survey and the North American Stratigraphic Code, but the database has not received a formal editorial review of geologic names.

Geologic map unit labels entered in database items LABL and PLABL contain substitute characters for conventional stratigraphic age symbols: Cambrian appears as ' $\mathrm{C}$ ' in LABL and as '_.' in PLABL, Mesozoic appears as 'Mz' in LABL and as ' $\}$ ' in PLABL, Pennsylvanian as 'P' in LABL and as ' $\&$ ' in PLABL, Triassic appears as 'Tr' in LABL and as ' $\wedge$ ' in PLABL, and Proterozoic appears as 'Pr' in LABl and as ' $<$ ' in PLABL. The substitute characters in PLABL invoke their corresponding symbols from the GeoAge font group to generate map unit labels with conventional stratigraphic symbols.

Time_Period_of_Content:

Time_Period_Information:

Range_of_Dates/Times:

Beginning_Date: 19750701

Ending_Date: 19961000

Currentness_Reference: New data

Status:

Progress: Complete

Maintenance_and_Update_Frequency: As needed

Spatial_Domain:

Bounding_Coordinates:

West_Bounding_Coordinate: -117.00009271

East_Bounding_Coordinate: -116.87490735

North_Bounding_Coordinate: 34.37499993

South_Bounding_Coordinate: 34.24998406 
Keywords:

Theme:

Theme_Keyword_Thesaurus: None

Theme_Keyword: geologic map

Theme_Keyword: geology

Theme_Keyword: bedrock geology

Theme_Keyword: surficial geology

Place:

Place_Keyword_Thesaurus: None

Place_Keyword: California

Place_Keyword: San Bernardino County

Place_Keyword: San Bernardino Mountains

Place_Keyword: Fawnskin 7.5' quadrangle

Stratum:

Stratum_Keyword_Thesaurus: None

Stratum_Keyword: Triassic monzonite

Stratum_Keyword: Cataclasite

Stratum_Keyword: Young faults

Stratum_Keyword: Paleozoic carbonate rock

Stratum_Keyword: Cretaceous granitic rocks

Stratum_Keyword: Jurassic granitic rocks

Access_Constraints: None

Use_Constraints:

The Fawnskin 7.5' geologic-map database should be used to evaluate and understand the geologic character of the Fawnskin 7.5' quadrangle as a whole. The data should not be used for purposes of site-specific land-use planning or site-specific geologic evaluations. The database is sufficiently detailed to identify and characterize geologic materials and structures. However, it is not sufficiently detailed for site-specific determinations.

Use of this digital geologic map database should not violate the spatial resolution of the data. Although the digital form of the data removes the constraint imposed by the scale of a paper map, the detail and accuracy inherent in map scale are also present in the digital data. The fact that this database was compiled and edited at a scale of 1:24,000 means that higher resolution information may not have been uniformly retained in the dataset. Plotting at scales larger than 1:24,000 will not yield greater real detail, although it may reveal fine-scale irregularities below the intended resolution of the database. Similarly, although higher resolution data is incorporated in most of the map, the resolution of the combined output will be limited by the lower resolution data.

Point_of_Contact:

Contact_Information:

Contact_Person_Primary:

Contact_Person: F.K. Miller

Contact_Organization: U.S.Geological Survey, Western Region, Earth Surface Processes Team

Contact_Position: Project geologist

Contact_Address:

Address_Type: mailing

Address:

U.S. Geological Survey

W904 Riverside Avenue

City: Spokane

State_or_Province: Washington

Postal_Code: 99201-1087

Country: USA

Contact_Voice_Telephone: 5093683121

Contact_Electronic_Mail_Address: fmiller@usgs.gov

Browse_Graphic: 
Browse_Graphic_File_Name: http://geopubs.wr.usgs.gov/open-file/of98-579/images/fskn_browse.jpg Browse_Graphic_File_Description:

Non-navigable .jpg image of the geologic map, topographic base, Correlation of Map Units, Description of Map Units and key to point and line symbols.

Browse_Graphic_File_Type:.jpg

Browse_Graphic:

Browse_Graphic_File_Name: http://geopubs.wr.usgs.gov/open-file/of98-579/images/fskn_map.pdf

Browse_Graphic_File_Description:

Navigable portable document file (.pdf) image of the geologic map, topographic base,

Correlation of Map Units, Description of Map Units and key to point and line symbols.

Browse_Graphic_File_Type: Portable document format, .pdf

Data_Set_Credit:

Technical review by Douglas M. Morton led to significant improvements that eventually were reflected in aspects of the database, the plot file, and in the description of the geologic units of the Fawnskin 7.5' quadrangle. Digital review by R.W. Grymer allowed us to produce a much improved product.

Geologic mapping and digital preparation of this report were sponsored jointly by (1) the National Cooperative Geologic Mapping Program of the U.S. Geological Survey, (2) the California Division of Mines and Geology, and (3) the Southern California Areal Mapping Project (SCAMP). In our digital preparation of the data set, initiated in the SCAMP Geographic Information System laboratory in Riverside, California by Gregory Morton and completed in the Geographic Information System laboratory of the Mineral Resources Program of the U.S. Geological Survey in Spokane, Washington by Pamela M. Cossette, we received valuable assistance from Paul C. Hyndman in Spokane, Washington, and from Rachel Alvarez in Riverside.

Native_Data_Set_Environment: SunOS, 5.6, sun4u UNIX ARC/INFO version 7.2.1

Cross_Reference:

Citation_Information:

Originator: Fred K. Miller

Originator: Jonathan C. Matti

Originator: Howard J. Brown

Publication_Date: 2000301

Title: Digital geologic map of the Butler Peak 7.5' quadrangle, San Bernardino County, California Edition: Version 1.0

Geospatial_Data_Presentation_Form: vector digital data

Series_Information:

Series_Name: U.S. Geological Survey Open-File Report

Issue_Identification: USGS OF 00-145

Publication_Information:

Publication_Place: Menlo Park, California

Publisher: U.S. Geological Survey

Online_Linkage: http://geopubs.wr.usgs.gov/open-file/of00-145

Data_Quality_Information:

Attribute_Accuracy:

Attribute_Accuracy_Report:

Geologic-map units in the Fawnskin quadrangle database were described using standard field methods. Consistent with these methods, the database author has assigned standard geologic attributes to geologic lines, points, and polygons identified in the database.

Nation-wide geologic-map accuracy standards have not been developed and adopted by the U.S. Geological Survey and other earth-science entities. Until such standards are adopted, the

SCAMP project has developed internal map-accuracy standards for 1:24,000-scale geologic maps produced by the project.

Geologic lines and points on 1:24,000 scale geologic maps are judged to meet SCAMP's 
internal map-accuracy standards if they are located to within 15 meters, relative to topographic or cultural features on the base map.

Lines and points that meet (or may not meet) this SCAMP internal map-accuracy standard are identified both in the digital database and on derivative geologic-map plots. Within the database, line and point data that are judged to meet the SCAMP internal map-accuracy standard are denoted by the attribute code .MEE. (meets) in the appropriate data table; line and point data that may not meet the SCAMP internal map-accuracy standard are denoted by the attribute code .MNM. (may not meet).

On any derivative geologic-map plot, line data that are judged to meet the SCAMP internal map-accuracy standard are denoted by solid lines; line data that may not meet the SCAMP internal map-accuracy standard are denoted by dashed or dotted lines. There is no cartographic device for denoting the map-accuracy for geologic-point data (eg. symbols representing bedding, foliation, lineations, etc.).

Logical_Consistency_Report:

Polygon and chain-node topology present.

The areal extent of the map is represented digitally by an appropriately projected (polyconic projection), mathematically generated box. Consequently, polygons intersecting the lines that comprise the map boundary are closed by that boundary. Polygons internal to the map boundary are completely enclosed by line segments which are themselves a set of sequentially numbered coordinate pairs. Point data are represented by coordinate pairs.

Completeness_Report:

The geologic map and digital database of the Fawnskin 7.5' quadrangle, version 1.1, contain new data that have been subjected to rigorous review and are a substantially complete representation of the current state of knowledge concerning the geology of the quadrangle. Positional_Accuracy:

Horizontal_Positional_Accuracy:

Horizontal_Positional_Accuracy_Report:

The maximum transformation RMS error acceptable for 7.5' quadrangle transformation and data input is 0.003 (1.8 meters). Horizontal positional accuracy was checked by visual comparison of hard-copy plots with base-stable source data.

Lineage:

Process_Step:

Process_Description:

Field mapping and aerial photograph interpretation; iterative process (F.K. Miller, J.C.

Matti, and H.J. Brown).

Process_Date: 1975-1996

Process_Step:

Process_Description:

Transfer of geologic linework and point data from field maps and aerial photographs to a scale-stable cartographic base of quadrangle (scribeguide) (F.K. Miller and J.C. Matti).

Process_Date: 1996

Process_Step:

Process_Description: Description of Map Units and Correlation of Map Units (F.K.Miller)

Process_Date: 1997

Process_Step:

Process_Description:

Preparation of a .007 mil, right-reading, black line clear film made by contact photographic processes.

Process_Date: 1997

Process_Step:

Process_Description:

Hand-digitization of the clear-film, right-reading, 0.007 mil thickness, base-stable blackline positive (made by contact photograph from a scribeguide) of the author-prepared 
geologic map at 1:24,000 scale, in the SCAMP Riverside, CA GIS lab. (G. Morton, S.

Kennedy).

Process_Date: 1997-1998

Process_Step:

Process_Description: Lines added and existing lines modified (P.M. Cossette).

Process_Date: 1997-1998

Process_Step:

Process_Description:

ARC/INFO database established; cleanup of digitizing artifacts; polygon, arc, and point attribute tables established using model developed for SCAMP coverages. Digitizing and editing artifacts significant enough to display at a scale of 1:24,000 were corrected (P.M.

Cossette).

Process_Date: 1997-1998

Process_Step:

Process_Description:

First draft of metadata for Version 1.0 created by Jennifer Lenz, USGS, using FGDCMETA.AML ver. 1.2 05/14/98 on ARC/INFO data set fskn_geo.

Process_Date: 20000720

Process_Step:

Process_Description:

Second draft of metadata for Version 1.1 created by P.Cossette using FGDCMETA.AML ver. 1.2 06/13/98 on ARC/INFO data set/pool5/b/pcossette/fskn-newof/fskn_geo0302

Process_Date: 20010302

Spatial_Data_Organization_Information:

Direct_Spatial_Reference_Method: vector

Point_and_Vector_Object_Information:

SDTS_Terms_Description:

SDTS_Point_and_Vector_Object_Type: Point

Point_and_Vector_Object_Count: 1559

SDTS_Point_and_Vector_Object_Type: String

Point_and_Vector_Object_Count: 4301

SDTS_Point_and_Vector_Object_Type: GT-polygon composed of chains

Point_and_Vector_Object_Count: 1560

Spatial_Reference_Information:

Horizontal_Coordinate_System_Definition:

Planar:

Map_Projection:

Map_Projection_Name: Polyconic

Polyconic:

Longitude_of_Central_Meridian:-116.9375

Latitude_of_Projection_Origin: 34.2500

False_Easting: 0.00000

False_Northing: 0.00000

Planar_Coordinate_Information:

Planar_Coordinate_Encoding_Method: coordinate pair

Coordinate_Representation:

Abscissa_Resolution: 0.0027669090777

Ordinate_Resolution: 0.0027669090777

Planar_Distance_Units: Meters

Geodetic_Model:

Horizontal_Datum_Name: North American Datum of 1927

Ellipsoid_Name: Clarke 1866

Semi-major_Axis: 6378206.4

Denominator_of_Flattening_Ratio: 294.98

Entity_and_Attribute_Information:

Overview_Description: 
Entity_and_Attribute_Overview:

The digital geologic map of the Fawnskin 7.5' quadrangle includes five geospatial datasets as double precision ARC/INFO coverages: fskn_geo (geology), fskn_pts (structural point data), fskn_str (structural line data), fskn_orn (line ornamentation) and fskn_ldr (annotation leaders). Geospatial entities in ARC/INFO coverages have the following software-defined attributes: <cover>.pat contains AREA, PERIMETER, cover\#, and cover-ID; <cover> aat contains FNODE\#, TNODE\#, LPOLY\#, RPOLY\#, LENGTH, cover\#, and cover-ID. User-defined attributes are described in detail below.

(1) The coverage fskn_geo includes a polygon feature attribute table (fskn_geo.pat) that describes the geospatial distribution of rock units represented in the Postscript (.ps) and Portable Document Format (.pdf) plotfiles of the geologic maps and an arc feature attribute table (fskn_geo.aat) that describes the contacts and faults that bound rock-unit polygons. Line and point identity data are recorded in the .aat and .pat using a system of identity codes. Two INFO tables, lines.rel and points.rel, provide a full description of each of the geological line and point codes in the database. For display purposes in the .ps and .pdf geologic maps, the geology coverage includes two annotation subclasses: anno.geo, which contains unit labels derived from the coded item PLABL, and anno.fault, which contains formal fault names. In addition, the item TAG allows the user to access (relate to) a series of INFO data tables that contain additional, detailed, coded geologic data. A complete description of the polygon, line, and point data coding schemes is available in U.S. Geological Survey Open-File Reports 97-859, OFR 97-860, and OFR 97-861 (full source citations follow).

Six INFO data tables are included in the Fawnskin database: fawnskin_summary.rel provides general information attribute data, fawnskin_genesis.rel provides data summarizing the genesis of each of the major rock types that occur within a particular map rock unit, fawnskin_lithology.rel contains lithologic attributes for the main and secondary lithologic types in the geologic-map unit, fawnskin_paleontology.rel contains attributes that summarize information about fossil type occurrences in each of the rock types, fawnskin_protolith.rel describes rock type protoliths, and fawnskin_structure.rel contains geologic structural data. The tables have identical architecture other than fawnskin_summary.rel. The item TAG serves as the relate item and there are five additional feature attribute items, LITH1...LITH5, that represent the major rock types within a rock unit. Fawnskin_summary.rel contains seven items: TAG (the relate item), AGE (unit age), AGECON (the confidence with which a geologic age is assigned to a map unit), SURFACE (geologic and geomorphic properties that characterize the upper surface of surficial geologic units), TYPE (hierarchical classification of the specific lithologic types occurring in the map unit), CLASS (stratigraphic classification of a rock unit per the North American Code of Stratigraphic Nomenclature), and ORIGIN (geologic origin of each map unit).

(2) The coverage fskn_pts includes a point attribute table (fskn_pts.pat) that describes both the types and orientation of bedding, foliation, and lineation. An annotation subclass displays the dip or plunge values associated with the point data.

(3) The coverage fskn_str includes an arc attribute table (fskn_str.aat) that describes linear, geologic structural data.

(4) The coverage fskn_orn includes a point attribute table (fskn_orn.pat) that describes structural line ornamentation.

(5) The coverage fskn_ldr includes an arc attribute table (fskn_ldr.pat) that describes annotation leaders. Unit symbols that are placed outside the perimeter of a particular polygon identify that polygon with annotation leaders. 
Entity_and_Attribute_Detail_Citation:

A complete description of the polygon, line, and point data coding schemes is available in the following U.S. Geological Survey Open-File Reports:

Matti, J.C., Miller, F.K., Powell, R.E., Kennedy, S.A., Bunyapanasarn, T.P., Koukladas, Catherine, Hauser, R.M., and Cossette, P.M., 1997b, Geologic-point attributes for digital geologic-map databases produced by the Southern California Areal Mapping Project (SCAMP), Version 1.0: U.S.Geological Survey Open-File Report 97-859

Matti, J.C., Miller, F.K., Powell, R.E., Kennedy, S.A., and Cossette, P.M., 1997c,

Geologic-polygon attributes for digital geologic-map databases produced by the Southern California Areal Mapping Project (SCAMP), Version 1.0: U.S.Geological Survey Open-File Report 97-860

Matti, J.C., Powell, R.E., Miller, F.K., Kennedy, S.A., Ruppert, K.R., Morton, G.L., and Cossette, P.M., 1997a, Geologic-line attributes for digital geologic-map databases produced by the Southern California Areal Mapping Project (SCAMP), Version 1.0: U.S.Geological Survey Open-File Report 97-861

Detailed_Description:

Entity_Type:

Entity_Type_Label: FSKN_GEO.PAT

Entity_Type_Definition: Geologic map units

Attribute:

Attribute_Label: LABL

Attribute_Definition:

Geologic map unit label. Plain text is substituted for conventional geologic age symbols (C

for Cambrian, Mz for Mesozoic, Tr for Triassic, P for Pennsylvanian, and Pr for Proterozoic)

and unit label subscripts as annotated on map

Attribute_Domain_Values:

Enumerated_Domain:

Enumerated_Domain_Value: Qaf

Enumerated_Domain_Value_Definition: Artificial Fill (late Holocene)

Enumerated_Domain:

Enumerated_Domain_Value: Qw

Enumerated_Domain_Value_Definition: Active-wash deposits (late Holocene)

Enumerated_Domain:

Enumerated_Domain_Value: Qf

Enumerated_Domain_Value_Definition: Deposits of alluvial fans (late Holocene)

Enumerated_Domain:

Enumerated_Domain_Value: Qa

Enumerated_Domain_Value_Definition: Deposits of axial valley floors (late Holocene)

Enumerated_Domain:

Enumerated_Domain_Value: Qc

Enumerated_Domain_Value_Definition: Colluvial deposits (late Holocene)

Enumerated_Domain:

Enumerated_Domain_Value: Qt

Enumerated_Domain_Value_Definition: Talus deposits (late Holocene)

Enumerated_Domain:

Enumerated_Domain_Value: Qls

Enumerated_Domain_Value_Definition: Landslide deposits (late Holocene)

Enumerated_Domain:

Enumerated_Domain_Value: Qs

Enumerated_Domain_Value_Definition: Undifferentiated alluvial deposits (late Holocene)

Enumerated_Domain:

Enumerated_Domain_Value: Qyf

Enumerated_Domain_Value_Definition: Young deposits of alluvial fans (Holocene and late Pleistocene) 
Enumerated_Domain:

Enumerated_Domain_Value: Qyf5

Enumerated_Domain_Value_Definition: Young deposits of alluvial fans, unit 5 (late Holocene)

Enumerated_Domain:

Enumerated_Domain_Value: Qyf4

Enumerated_Domain_Value_Definition: Young deposits of alluvial fans, unit 4 (late Holocene)

Enumerated_Domain:

Enumerated_Domain_Value: Qyf3

Enumerated_Domain_Value_Definition: Young deposits of alluvial fans, unit 3 (late and middle Holocene)

Enumerated_Domain:

Enumerated_Domain_Value: Qyf2

Enumerated_Domain_Value_Definition: Young deposits of alluvial fans, unit 2 (early Holocene)

Enumerated_Domain:

Enumerated_Domain_Value: Qyf1

Enumerated_Domain_Value_Definition: Young deposits of alluvial fans, unit 1 (early Holocene and late Pleistocene)

Enumerated_Domain:

Enumerated_Domain_Value: Qya

Enumerated_Domain_Value_Definition: Young deposits of axial valley floors (Holocene and late Pleistocene)

Enumerated_Domain:

Enumerated_Domain_Value: Qyc

Enumerated_Domain_Value_Definition: Young colluvial deposits (Holocene and late Pleistocene)

Enumerated_Domain:

Enumerated_Domain_Value: Qyt

Enumerated_Domain_Value_Definition: Young talus deposits (Holocene and late Pleistocene)

Enumerated_Domain:

Enumerated_Domain_Value: Qyls

Enumerated_Domain_Value_Definition: Young landslide deposits (Holocene and late Pleistocene)

Enumerated_Domain:

Enumerated_Domain_Value: Qys

Enumerated_Domain_Value_Definition: Young surficial deposits undifferentiated (Holocene and late

Pleistocene)

Enumerated Domain:

Enumerated_Domain_Value: Qof

Enumerated_Domain_Value_Definition: Old deposits of alluvial fans (late to middle Pleistocene)

Enumerated_Domain:

Enumerated_Domain_Value: Qof3

Enumerated_Domain_Value_Definition: Old deposits of alluvial fans, unit 3 (late Pleistocene)

Enumerated_Domain:

Enumerated_Domain_Value: Qof2

Enumerated_Domain_Value_Definition: Old deposits of alluvial fans, unit 2 (late Pleistocene)

Enumerated_Domain:

Enumerated_Domain_Value: Qoa

Enumerated_Domain_Value_Definition: Old deposits of allvial-valley floors, undifferentiated (late to middle

Pleistocene)

Enumerated_Domain:

Enumerated_Domain_Value: Qot

Enumerated_Domain_Value_Definition: Old talus deposits (late to middle Pleistocene)

Enumerated_Domain:

Enumerated_Domain_Value: Qols

Enumerated_Domain_Value_Definition: Old landslide deposits (late to middle Pleistocene)

Enumerated_Domain:

Enumerated_Domain_Value: Qos

Enumerated_Domain_Value_Definition: Old surficial deposits undifferentiated (late to middle Pleistocene)

Enumerated_Domain:

Enumerated_Domain_Value: Qvof 
Enumerated_Domain_Value_Definition: Very old deposits of alluvial fans (middle to early Pleistocene)

Enumerated_Domain:

Enumerated_Domain_Value: Qvof3

Enumerated_Domain_Value_Definition: Very old deposits of alluvial fans, unit 3 (early Pleistocene)

Enumerated_Domain:

Enumerated_Domain_Value: Qvof2

Enumerated_Domain_Value_Definition: Very old deposits of alluvial fans, unit 2 (early Pleistocene)

Enumerated_Domain:

Enumerated_Domain_Value: Qvols

Enumerated_Domain_Value_Definition: Very old landslide deposits (middle to early Pleistocene)

Enumerated_Domain:

Enumerated_Domain_Value: Qvos

Enumerated_Domain_Value_Definition: Very old surficial deposits, undifferentiated (late to middle Pleistocene)

Enumerated_Domain:

Enumerated_Domain_Value: Qvobc

Enumerated_Domain_Value_Definition: Very old deposits of catastrophic carbonate breccia (early Pleistocene)

Enumerated_Domain:

Enumerated_Domain_Value: Qvobg

Enumerated_Domain_Value_Definition: Very old deposits of catastrophic granitic breccia (early Pleistocene)

Enumerated_Domain:

Enumerated_Domain_Value: QTcp

Enumerated_Domain_Value_Definition: Conglomerate, porphyry-bearing facies (Pleistocene? and Pliocene?)

Enumerated_Domain:

Enumerated_Domain_Value: QTcc

Enumerated_Domain_Value_Definition: Conglomerate, Cushenberry facies (Pleistocene? and Pliocene?)

Enumerated_Domain:

Enumerated_Domain_Value: QTsc

Enumerated_Domain_Value_Definition: Sandstone and conglomerate (Pleistocene? and Pliocene?)

Enumerated_Domain:

Enumerated_Domain_Value: QTscp

Enumerated_Domain_Value_Definition: Sandstone and conglomerate, porphyry facies (Pleistocene? and

Pliocene?)

Enumerated_Domain:

Enumerated_Domain_Value: QTscc

Enumerated_Domain_Value_Definition: Sandstone and conglomerate, Cushenberry facies (Pleistocene? and

Pliocene?)

Enumerated_Domain:

Enumerated_Domain_Value: QTom

Enumerated_Domain_Value_Definition: Old Woman Sandstone, mudrock and sandstone member (Pleistocene? and Pliocene?)

Enumerated_Domain:

Enumerated_Domain_Value: QTos

Enumerated_Domain_Value_Definition: Old Woman Sandstone, sandstone memeber (Pleistocene? and Pliocene?)

Enumerated_Domain:

Enumerated_Domain_Value: Ts4

Enumerated_Domain_Value_Definition: Sedimentary rocks south of Big Bear Lake (Miocene?)

Enumerated_Domain:

Enumerated_Domain_Value: Ts3

Enumerated_Domain_Value_Definition: Sedimentary rocks south of Bertha Ridge and John Bull Mountain

(Miocene?)

Enumerated_Domain:

Enumerated_Domain_Value: Ts2

Enumerated_Domain_Value_Definition: Sedimentary rocks of Poligue Canyon (Miocene?)

Enumerated_Domain:

Enumerated_Domain_Value: Ts1 
Enumerated_Domain_Value_Definition: Sedimentary rocks of Holocomb Valley (Miocene?)

Enumerated_Domain:

Enumerated_Domain_Value: Ts

Enumerated_Domain_Value_Definition: Sandstone (Miocene?)

Enumerated_Domain:

Enumerated_Domain_Value: Mzu

Enumerated_Domain_Value_Definition: Undivided granitic rocks of range front (Cretaceous to Jurassic)

Enumerated_Domain:

Enumerated_Domain_Value: Kbm

Enumerated_Domain_Value_Definition: Biotite monzogranite (Cretaceous)

Enumerated_Domain:

Enumerated_Domain_Value: Kb

Enumerated_Domain_Value_Definition: Monzogranite of John Bull Flat (Cretaceous)

Enumerated_Domain:

Enumerated_Domain_Value: Ks

Enumerated_Domain_Value_Definition: Monzogranite of Stanfield Cutoff (Cretaceous)

Enumerated_Domain:

Enumerated_Domain_Value: Kbp

Enumerated_Domain_Value_Definition: Monzogranite of Butler Peak (Cretaceous)

Enumerated_Domain:

Enumerated_Domain_Value: Kk

Enumerated_Domain_Value_Definition: Monzogranite of Keller Peak (Cretaceous)

Enumerated_Domain:

Enumerated_Domain_Value: Kh

Enumerated_Domain_Value_Definition: Granodiorite of Hanna Flat (Cretaceous)

Enumerated_Domain:

Enumerated_Domain_Value: Kgc

Enumerated_Domain_Value_Definition: Monzogranite of Greenlead Creek (Creteacous)

Enumerated_Domain:

Enumerated_Domain_Value: KJb

Enumerated_Domain_Value_Definition: Granodiorite of Bousic Canyon (Cretaceous or Jurassic)

Enumerated_Domain:

Enumerated_Domain_Value: KJdg

Enumerated_Domain_Value_Definition: Mafic mafic diorite and gabbro (Cretaceous or Jurassic)

Enumerated_Domain:

Enumerated_Domain_Value: KJ1

Enumerated_Domain_Value_Definition: Leucocratic granitic rocks (Cretaceous to Jurassic)

Enumerated_Domain:

Enumerated_Domain_Value: Jh

Enumerated_Domain_Value_Definition: Volcanic and hypabyssal rocks of Holcomb Valley area (Jurassic?)

Enumerated_Domain:

Enumerated_Domain_Value: Jcr

Enumerated_Domain_Value_Definition: Cataclastic rocks (Jurassic)

Enumerated_Domain:

Enumerated_Domain_Value: Jb

Enumerated_Domain_Value_Definition: Bertha Peak Pluton of Cameron (1981) (Jurassic)

Enumerated_Domain:

Enumerated_Domain_Value: Jfc

Enumerated_Domain_Value_Definition: Quartz monzonite porphyry of Furnace Canyon Jurassic)

Enumerated_Domain:

Enumerated_Domain_Value: Jc

Enumerated_Domain_Value_Definition: Leucocratic quartz monzonite of Crystal Creek (Jurassic)

Enumerated_Domain:

Enumerated_Domain_Value: Jd

Enumerated_Domain_Value_Definition: Quartz monzodiorite of Dry Canyon (Jurassic)

Enumerated_Domain: 
Enumerated_Domain_Value: Jdm

Enumerated_Domain_Value_Definition: Deformed monzogranite of hill 4970 (Jurassic)

Enumerated_Domain:

Enumerated_Domain_Value: Jsc

Enumerated_Domain_Value_Definition: Fine-grained rocks of Silver Canyon (Jurassic)

Enumerated_Domain:

Enumerated_Domain_Value: Trf

Enumerated_Domain_Value_Definition: Monzonite of Fawnskin (Triassic)

Enumerated_Domain:

Enumerated_Domain_Value: Pbuc

Enumerated_Domain_Value_Definition: Bird Spring Formation, upper carbonate member (Pennsylvanian)

Enumerated_Domain:

Enumerated_Domain_Value: Pbmc

Enumerated_Domain_Value_Definition: Bird Spring Formation, middle carbonate member (Pennsylvanian)

Enumerated_Domain:

Enumerated_Domain_Value: Pblc

Enumerated_Domain_Value_Definition: Bird Spring Formation, lower carbonate member (Pennsylvanian)

Enumerated_Domain:

Enumerated_Domain_Value: Pbsc

Enumerated_Domain_Value_Definition: Bird Spring Formation, siltstone and carbonate Member

(Pennsylvanian)

Enumerated_Domain:

Enumerated_Domain_Value: Pbq

Enumerated_Domain_Value_Definition: Bird Spring Formation, quartzite member (Pennsylvanian)

Enumerated_Domain:

Enumerated_Domain_Value: Mmy

Enumerated_Domain_Value_Definition: Monte Cristo Limestone, Yellowpine Member (Mississippian)

Enumerated_Domain:

Enumerated_Domain_Value: Mmb

Enumerated_Domain_Value_Definition: Monte Cristo Limestone, Bullion Member (Mississippian)

Enumerated_Domain:

Enumerated_Domain_Value: Mml

Enumerated_Domain_Value_Definition: Monte Cristo Limestone, lower member (Mississippian)

Enumerated_Domain:

Enumerated_Domain_Value: Dsc

Enumerated_Domain_Value_Definition: Sultan Limestone, Crystal Pass Member (Devonian)

Enumerated_Domain:

Enumerated_Domain_Value: Dsv

Enumerated_Domain_Value_Definition: Sultan Limestone, Valentine Member (Devonian)

Enumerated_Domain:

Enumerated_Domain_Value: Dsi

Enumerated_Domain_Value_Definition: Sultan Limestone, Ironside Member (Devonian)

Enumerated_Domain:

Enumerated_Domain_Value: Cn

Enumerated_Domain_Value_Definition: Nopah Formation (Cambrian)

Enumerated_Domain:

Enumerated_Domain_Value: Cnd

Enumerated_Domain_Value_Definition: Dunderburg Shale Member (Cambrian)

Enumerated_Domain:

Enumerated_Domain_Value: $\mathrm{Cb}$

Enumerated_Domain_Value_Definition: Bonanza King Formation, undivided (Camb rian)

Enumerated_Domain:

Enumerated_Domain_Value: Cba

Enumerated_Domain_Value_Definition: Bonanza King Formation, argillaceous marker unit (Cambrian)

Enumerated_Domain:

Enumerated_Domain_Value: Cbdg 
Enumerated_Domain_Value_Definition: Bonanza King Formation, gray dolomite member (Cambrian)

Enumerated_Domain:

Enumerated_Domain_Value: Cbdw

Enumerated_Domain_Value_Definition: Bonanza King Formation, white dolomite member (Cambrian)

Enumerated_Domain:

Enumerated_Domain_Value: Cbm

Enumerated_Domain_Value_Definition: Bonanza King Formation, middle member (Cambrian)

Enumerated_Domain:

Enumerated_Domain_Value: Cbl

Enumerated_Domain_Value_Definition: Bonanza King Formation, lower member (Cambrian)

Enumerated_Domain:

Enumerated_Domain_Value: Cc

Enumerated_Domain_Value_Definition: Carrara Formation (Cambrian)

Enumerated_Domain:

Enumerated_Domain_Value: Cz

Enumerated_Domain_Value_Definition: Zabriskie Quartzite (Cambrain)

Enumerated_Domain:

Enumerated_Domain_Value: Cw

Enumerated_Domain_Value_Definition: Wood Canyon Formation (Cambrian)

Enumerated_Domain:

Enumerated_Domain_Value: Prsq

Enumerated_Domain_Value_Definition: Stirling Quartzite, quartzite member (late Proterozoic)

Enumerated_Domain:

Enumerated_Domain_Value: Prscq

Enumerated_Domain_Value_Definition: Stirling Quartzite, carbonate and quartzite member (late Proterozoic) Attribute:

Attribute_Label: SHDFIL

Attribute_Definition: Coded integer value that relates polygon to fill pattern in shadeset, geology2.shd.

Attribute:

Attribute_Label: PLABL

Attribute_Definition: Coded geologic map unit label used to generate plot label.

Attribute:

Attribute_Label: NAME

Attribute_Definition: Geologic name of map unit (see list under LABL attribute).

Attribute:

Attribute_Label: TAG

Attribute_Definition:

A reference label for subgroups of polygons of the geologic-map unit identified by LABL.

Each polygon subgroup has certain attributes in common with all other polygons of the map

unit. However, each subgroup may have unique, distinguishing attributes which warrant

recognition in the database although those distinguishing characteristics do not warrant

recognition as new map units.

TAG is defined as LABL followed by an upper-case letter, e.g., QwA, QwB, or QwC, etc. There are many units in the Fawnskin quadrangle that have sufficiently distinctive properties that are identified with TAG other than the dafault A designation.

TAG serves one additional purpose: it functions as the relate item that associates each polygon with its attributes stored in the six polygon-attribute data tables identified in the Entity_and_Attribute_Overview section above.

Attribute:

Attribute_Label: SHDPS

Attribute_Definition:

Polygon color from shadeset scamp2.shd (included in the data package) and used to generate the map plotfile.

Attribute: 
Attribute_Label: POLYCON

Attribute_Definition:

Coded statement of confidence with which the unit assignment was made (See

Entity_and_Attribute_Detail_Citation section).

Detailed_Description:

Entity_Type:

Entity_Type_Label: FSKN_GEO.AAT

Entity_Type_Definition: Geologic contacts and faults that bound rock-unit polygons.

Attribute:

Attribute_Label: L-SYMB

Attribute_Definition: Coded integer symbol that relates arc to cartographic line symbol in lineset, geoscamp2.lin.

Attribute:

Attribute_Label: L-TAG

Attribute_Definition:

Coded alpha-numerical symbol that relates arc to definition of line type in dictionary,

lines.rel. For description of attributes in line classification dictionary, refer to USGS

Open-File Report 97-861 (see Entity_and_Attribute_Detail_Citation)

Attribute_Domain_Values:

Enumerated_Domain:

Enumerated_Domain_Value: C1

Enumerated_Domain_Value_Definition: Contact, generic, location meets map accuracy standards

Enumerated_Domain:

Enumerated_Domain_Value: C18

Enumerated_Domain_Value_Definition: Contact, landslide, location may not meet map accuracy standards

Enumerated_Domain:

Enumerated_Domain_Value: C19

Enumerated_Domain_Value_Definition: Contact, landslide, inferred, location may not meet map accuracy standards

Enumerated_Domain:

Enumerated_Domain_Value: C25

Enumerated_Domain_Value_Definition: Contact, landslide crown scarp, location meets map accuracy standards

Enumerated_Domain:

Enumerated_Domain_Value: C26

Enumerated_Domain_Value_Definition: Contact, landslide crown scarp, location may not meet map accuracy standards

Enumerated_Domain:

Enumerated_Domain_Value: C29

Enumerated_Domain_Value_Definition: Contact, sedimentary, location may meet map accuracy standards

Enumerated_Domain:

Enumerated_Domain_Value: C30

Enumerated_Domain_Value_Definition: Contact, sedimentary, location may not meet map accuracy standards

Enumerated_Domain:

Enumerated_Domain_Value: C32

Enumerated_Domain_Value_Definition: Contact, sedimentary, inferred beneath mapped covering unit

Enumerated_Domain:

Enumerated_Domain_Value: C37

Enumerated_Domain_Value_Definition: Contact, separates terraced alluvial units, location meets map accuracy standards

Enumerated_Domain:

Enumerated_Domain_Value: C38

Enumerated_Domain_Value_Definition: Contact, separates terraced alluvial units, location may not meet map accuracy standards

Enumerated_Domain:

Enumerated_Domain_Value: C49

Enumerated_Domain_Value_Definition: Contact, igneous, location meets map accuracy standards

Enumerated_Domain: 
Enumerated_Domain_Value: C50

Enumerated_Domain_Value_Definition: Contact, igneous, location may not meet map accuracy standards

Enumerated_Domain:

Enumerated_Domain_Value: C51

Enumerated_Domain_Value_Definition: Contact, igneous, inferred, location meets map accuracy standards

Enumerated_Domain:

Enumerated_Domain_Value: CL1

Enumerated_Domain_Value_Definition: Cartographic line, map boundary

Enumerated_Domain:

Enumerated_Domain_Value: F1

Enumerated_Domain_Value_Definition: Fault, high-angle, slip unspecified, location meets map accuracy standards

Enumerated_Domain:

Enumerated_Domain_Value: F10

Enumerated_Domain_Value_Definition: Fault, high-angle, normal slip, location may not meet map accuracy standards

Enumerated_Domain:

Enumerated_Domain_Value: F162

Enumerated_Domain_Value_Definition: Fault, low-angle, thrust slip, older over younger, location meets map accuracy standards

Enumerated_Domain:

Enumerated_Domain_Value: F177

Enumerated_Domain_Value_Definition: Fault, low-angle, thrust slip, older over younger, location meets map accuracy standards

Enumerated_Domain:

Enumerated_Domain_Value: F178

Enumerated_Domain_Value_Definition: Fault, low-angle, thrust slip, older over younger, location may not meet map accuracy standards

Enumerated_Domain:

Enumerated_Domain_Value: F180

Enumerated_Domain_Value_Definition: Fault, low-angle, thrust slip, older over younger, inferred beneath mapped covering unit

Enumerated_Domain:

Enumerated_Domain_Value: F19 unit

Enumerated_Domain_Value_Definition: Fault, high-angle, slip unspecified, inferred beneath mapped covering

Enumerated_Domain:

Enumerated_Domain_Value: F193

Enumerated_Domain_Value_Definition:

Fault, low-angle, thrust slip, older over younger, has fault scarp, location meets map accuracy standards

Enumerated_Domain:

Enumerated_Domain_Value: F2

Enumerated_Domain_Value_Definition: Fault, high-angle, right-lateral strike-slip, location meets map accuracy standards

Enumerated_Domain:

Enumerated_Domain_Value: F20

Enumerated_Domain_Value_Definition: Fault, high-angle, right-lateral strike-slip, inferred beneath mapped covering unit

Enumerated_Domain:

Enumerated_Domain_Value: F205

Enumerated_Domain_Value_Definition: Fault, variable angle dip, rotational normal slip, location meets map accuracy standards

Enumerated_Domain:

Enumerated_Domain_Value: F206

Enumerated_Domain_Value_Definition: 
Fault, variable angle dip, rotational normal slip, location may not meet map accuracy

standards

Enumerated_Domain:

Enumerated_Domain_Value: F208

Enumerated_Domain_Value_Definition: Fault, variable angle dip, rotational normal slip, inferred beneath mapped covering unit

Enumerated_Domain:

Enumerated_Domain_Value: F22

Enumerated_Domain_Value_Definition: Fault, high-angle, normal slip, inferred beneath mapped covering unit

Enumerated_Domain:

Enumerated_Domain_Value: F220

Enumerated_Domain_Value_Definition: Fault, intruded, preintrusive existence inferred

Enumerated_Domain:

Enumerated_Domain_Value: F4

Enumerated_Domain_Value_Definition: Fault, high-angle, normal slip, location meets map accuracy standards

Enumerated_Domain:

Enumerated_Domain_Value: F5

Enumerated_Domain_Value_Definition: Fault, high-angle, reverse slip, location meets map accuracy standards

Enumerated_Domain:

Enumerated_Domain_Value: F53

Enumerated_Domain_Value_Definition: Fault, high-angle, reverse slip, has fault scarp, location meets map accuracy standards

Enumerated_Domain:

Enumerated_Domain_Value: F7

Enumerated_Domain_Value_Definition: Fault, high-angle, slip unspecified, location may not meet map accuracy standards

Enumerated_Domain:

Enumerated_Domain_Value: FZ1

Enumerated_Domain_Value_Definition: Fault zone boundary, scratch contact

Enumerated_Domain:

Enumerated_Domain_Value: FZ3

Enumerated_Domain_Value_Definition: Cataclastic zone boundary, scratch contact

Enumerated_Domain:

Enumerated_Domain_Value: GF10

Enumerated_Domain_Value_Definition: Geomorphic feature, lakeshore

Enumerated_Domain:

Enumerated_Domain_Value: GF7

Enumerated_Domain_Value_Definition: Geomorphic feature, topographic scarp, origin unknown

Attribute:

Attribute_Label: L-NAME

Attribute_Definition: Formal name of linear geologic feature.

Detailed_Description:

Entity_Type:

Entity_Type_Label: FSKN_PTS.PAT

Entity_Type_Definition: Structural point data.

Attribute:

Attribute_Label: P-DIP

Attribute_Definition: Dip of planar feature.

Attribute:

Attribute_Label: P-STRIKE

Attribute_Definition: Azimuthal strike of planar feature.

Attribute:

Attribute_Label: P-SYMB

Attribute_Definition:

Coded integer symbol that relates point to cartographic point symbol in markerset, geoscamp2.mrk. 
Attribute:

Attribute_Label: P-TAG

Attribute_Definition:

Coded alpha-numerical symbol that relates point to definition of point type in dictionary

look-up table (points.rel). For description of attributes in point classification

dictionary, refer to USGS Open-File Report 97-859 (see

Entity_and_Attribute_Detail_Citation).

Attribute_Domain_Values:

Enumerated_Domain:

Enumerated_Domain_Value: B2

Enumerated_Domain_Value_Definition: Bedding attitude, sedimentary, inclined

Enumerated_Domain:

Enumerated_Domain_Value: B4

Enumerated_Domain_Value_Definition: Bedding attitude, sedimentary, vertical

Enumerated_Domain:

Enumerated_Domain_Value: B6

Enumerated_Domain_Value_Definition: Bedding attitude, sedimentary, overturned

Enumerated_Domain:

Enumerated_Domain_Value: FN13

Enumerated_Domain_Value_Definition: Foliation attitude, igneous flow origin, inclined

Enumerated_Domain:

Enumerated_Domain_Value: FN31

Enumerated_Domain_Value_Definition: Foliation attitude, strain dominated origin, inclined

Enumerated_Domain:

Enumerated_Domain_Value: FN42

Enumerated_Domain_Value_Definition: Foliation attitude, metamorphic origin, inclined

Enumerated_Domain:

Enumerated_Domain_Value: FN43

Enumerated_Domain_Value_Definition: Foliation attitude, metamorphic origin, vertical

Enumerated_Domain:

Enumerated_Domain_Value: L16

Enumerated_Domain_Value_Definition: Lineation attitude, crushed and streaked mineral grains

Attribute:

Attribute_Label: P-DIPDIR

Attribute_Definition: Azimuthal direction of dip of planar feature.

Attribute:

Attribute_Label: P-PLUNGE

Attribute_Definition: Plunge of linear feature.

Attribute:

Attribute_Label: P-BEARING

Attribute_Definition: Azimuthal direction of plunge of linear feature.

Detailed_Description:

Entity_Type:

Entity_Type_Label: FSKN_STR.AAT

Entity_Type_Definition: Linear, structural features e.g. fold axes.

Attribute:

Attribute_Label: L-SYMB

Attribute_Definition: Stores appropriate line symbol value from the lineset geoscamp2.lin.

Attribute:

Attribute_Label: L-TAG

Attribute_Definition:

Coded alpha-numerical symbol that relates arc to definition of line type in dictionary,

lines.rel. For description of attributes in line classification dictionary, refer to USGS

Open-File Report 97-861 (see Entity_and_Attribute_Detail_Citation).

Attribute_Domain_Values:

Enumerated_Domain: 
Enumerated_Domain_Value: FA33

Enumerated_Domain_Value_Definition:

Fold axial trace, anticline, upright, subhorizontal plunge, location meets map accuracy

standards

Enumerated_Domain:

Enumerated_Domain_Value: FA36

Enumerated_Domain_Value_Definition:

Fold axial trace, anticline, upright, subhorizontal plunge, inferred beneath mapped covering unit

Enumerated_Domain:

Enumerated_Domain_Value: FA49

Enumerated_Domain_Value_Definition:

Fold axial trace, anticline, overturned, subhorizontal plunge, location meets map accuracy standards

Enumerated_Domain:

Enumerated_Domain_Value: FA97

Enumerated_Domain_Value_Definition:

Fold axial trace, syncline, upright, subhorizontal plunge, location meets map accuracy

standards

Enumerated_Domain:

Enumerated_Domain_Value: FA100

Enumerated_Domain_Value_Definition:

Fold axial trace, syncline, upright, subhorizontal plunge, inferred beneath mapped covering unit

Enumerated_Domain:

Enumerated_Domain_Value: FA113

Enumerated_Domain_Value_Definition:

Fold axial trace, syncline, overturned, subhorizontal plunge, location meets map accuracy standards

Detailed_Description:

Entity_Type:

Entity_Type_Label: FSKN_ORN.PAT

Entity_Type_Definition: Line ornamentation.

Attribute:

Attribute_Label: P-SYMB

Attribute_Definition:

Coded integer symbol that relates point to cartographic point symbol in markerset, geoscamp2.mrk.

Attribute:

Attribute_Label: P-TAG

Attribute_Definition:

Coded alpha-numerical symbol that relates point to definition of point type in dictionary

INFO table, points.rel. For description of attributes in point classification dictionary, refer to USGS Open-File Report 97-859 (see Entity_and_Attribute_Detail_Citation).

Attribute_Domain_Values:

Enumerated_Domain:

Enumerated_Domain_Value: FAC10

Enumerated_Domain_Value_Definition: Fold ornament, syncline, upright axial plane

Enumerated_Domain:

Enumerated_Domain_Value: FAC12

Enumerated_Domain_Value_Definition: Fold ornament, anticline, overturned axial plane

Enumerated_Domain:

Enumerated_Domain_Value: FAC4

Enumerated_Domain_Value_Definition: Fold ornament, anticline, upright axial plane

Enumerated_Domain:

Enumerated_Domain_Value: FAC6 
Enumerated_Domain_Value_Definition: Fold ornament, anticline, overturned axial plane Detailed_Description:

Entity_Type:

Entity_Type_Label: FSKN_LDR.AAT

Entity_Type_Definition: Annotation leaders.

Attribute:

Attribute_Label: L-SYMB

Attribute_Definition:

Coded integer symbol, value 1, that relates arcs to cartographic line symbol in lineset, geoscamp2.lin.

Distribution_Information:

Distributor:

Contact_Information:

Contact_Organization_Primary:

Contact_Organization: U.S. Geological Survey Information Services

Contact_Address:

Address_Type: mailing

Address: Box 25286, Denver Federal Center

City: Denver

State_or_Province: Colorado

Postal_Code: 80255-0046

Country: USA

Contact_Voice_Telephone: 1-888-ASK-USGS

Contact_Voice_Telephone: 303-202-4700

Contact_Facsimile_Telephone: 303-202-4693

Resource_Description: US Geological Survey Open-File Report 98-0579

Distribution_Liability:

The U.S. Geological Survey (USGS) provides these geographic data "as is." The USGS makes no guarantee or warranty concerning the accuracy of information contained in the geographic data. The USGS further makes no warranties, either expressed or implied as to any other matter whatsoever, including, without limitation, the condition of the product, or its fitness for any particular purpose. The burden for determining fitness for use lies entirely with the user. Although these data have been processed successfully on computers at the USGS, no warranty, expressed or implied, is made by the USGS regarding the use of these data on any other system, nor does the fact of distribution constitute or imply any such warranty.

In no event shall the USGS have any liability whatsoever for payment of any consequential, incidental, indirect, special, or tort damages of any kind, including, but not limited to, any loss of profits arising out of use of or reliance on the geographic data or arising out of delivery, installation, operation, or support by USGS.

This digital, geologic map database of the Fawnskin 7.5'quadrangle, 1:24,000 map-scale, and any derivative maps thereof, is not meant to be used or displayed at any scale larger than 1:24,000 (e.g., 1:12,000).

Metadata_Reference_Information:

Metadata_Date: 20010613

Metadata_Contact:

Contact_Information:

Contact_Person_Primary:

Contact_Person: Pamela M. Cossette

Contact_Organization: U.S. Geological Survey

Contact_Address:

Address_Type: mailing

Address: 904 West Riverside Avenue, Rm. 202

City: Spokane 
State_or_Province: WA

Postal_Code: 99201-1087

Country: USA

Contact_Voice_Telephone: (509) 368-3123

Contact_Facsimile_Telephone: (509) 368-3199

Contact_Electronic_Mail_Address: pcossette@usgs.gov

Metadata_Standard_Name: FGDC Content Standards for Digital Geospatial Metadata

Metadata_Standard_Version: FGDC-STD-001-1998

Metadata_Access_Constraints: None

Metadata_Use_Constraints: None 